\title{
Correction: Genome-wide gene-environment analyses of major depressive disorder and reported lifetime traumatic experiences in UK Biobank
}

\author{
Jonathan R. I. Coleman - Wouter J. Peyrot - Kirstin L. Purves (1) Katrina A. S. Davis - Christopher Rayner 1 \\ Shing Wan Choi - Christopher Hübel (10) Héléna A. Gaspar (1) - Carol Kan (1) - Sandra Van der Auwera • \\ Mark James Adams (iD) - Donald M. Lyall - Karmel W. Choi - on the behalf of Major Depressive Disorder \\ Working Group of the Psychiatric Genomics Consortium • Erin C. Dunn (D) Evangelos Vassos (D) - \\ Andrea Danese (D) - Barbara Maughan - Hans J. Grabe (D) C Cathryn M. Lewis (D) Paul F. O'Reilly (D) \\ Andrew M. Mclntosh (D) Daniel J. Smith (D) Naomi R. Wray (iD) Matthew Hotopf • Thalia C. Eley (D) Gerome Breen (iD
}

Published online: 18 May 2020

(c) Springer Nature Limited 2020

Correction to: Molecular Psychiatry https://doi.org/10.1038/s41380-019-0546-6 published online 23 January 2020

Following publication of this article, the authors noticed an error in Supplementary Table 1. In the original Supplementary Table 1, one of the criteria for control participants was incorrectly given as 'Report extensive recent symptoms of depression: less than $\mathbf{1 4}$ on summed response (where "not at all" = 1 and "nearly every day" =4) to recent'. This has now been corrected to: 'Report extensive recent symptoms of depression: less than $\mathbf{5}$ on summed response (where "not at all" = 1 and "nearly every day" =4) to recent'. 